\title{
Digital Student Preferences: a study of blended learning in Norwegian higher education
}

\author{
Charlie Keeling \\ Communication and Learning in Science, Chalmers University of Technology \\ keeling@chalmers.se \\ Astrid Haugestad \\ Kvadraturen Upper Secondary School \& University of Agder \\ astrid.haugestad@uia.no
}

\begin{abstract}
For fall term 2020, institutions of higher education globally were preparing to run courses as online or blended learning due to Covid-19 restrictions. The ideal situation is for a relatively seamless transition from campus-based teaching to blended and/or online. The aim of this study is to examine the experience of a single cohort of students in order to identify trends in student preferences. The research model was mixed-method quantitative and qualitative analysis. The main research question is: What are student preferences for blended learning? The survey and interview results are from trainee teachers in a municipality in Norway in 2018 to 2019. The main research group consisted of 18 respondents from a group of 28 students with a response rate of $64 \%$. Four students were selected for semi-structured interviews. A clear majority of the students favor the use of blended learning. They experienced little difference in terms of teacher-centred practice and cooperative learning, i.e. traditional lectures and teacher-led tasks. In contrast, student-centred practice and collaborative learning were strongly favored as campus-based. The loss of social cohesion and more productive student-student dialogue and collaboration is clear. In addition, the data implies that lecturing could be effectively delivered online.
\end{abstract}

Keywords: Blended learning, cooperative learning, collaborative learning, student-centred practice 


\section{Introduction}

According to a report from the Norwegian Ministry of Education (Digitalization strategy for the higher education sector, 2017-2021), digitalization will create opportunities for new and different learning and teaching processes, as well as new forms of organization and communi- cation. Digitalization, combined with decentralization, has gained some attention in both the Norwegian press and professional journals as well as in the Ministry of Education report (Holterman, 2019; Utdanning 3, 2019). Most of the literature on digitalization links it to education equality. The decentralized model and increased digitalization together contribute to achieving the twin objectives of improved education and research.

A decentralized teacher education seems to be an important part of the educational system for recruiting qualified teachers in remote and rural areas of Norway. The respondents in this study were enrolled in a teacher training course in a municipality in northern Norway. The course syllabus goals were to produce qualified English teachers for primary education. The course was a pilot course in digitalized and decentralized education. In terms of content, it was not only a traditional English language and literature course, i.e. language learning, but also a course in educational methodology. Moreover, the delivery model of blended learning made the education possible, as teachers and teaching materials were provided from a university in southern Norway. Weekly online tuition in a Virtual Learning Environment (VLE) was augmented by three course meetings per term with students drawn from the entire municipality. Foundational material was provided via the VLE and synchronous online tuition was provided via an integrated video conferencing and meeting tool.

Terms such as blended learning or hybrid learning, i.e. technology-based learning solutions, have been applied to digitalization and decentralization at an administrative or organizational level in the past. Many define blended learning as a combination of pedagogical approaches (Garrison \& Kanuka, 2004). Moreover, it represents an educational and pedagogical choice to improve learning in any course combining traditional and digital methods. Decentralization, in contrast, encompasses a societal project of education equality and renewal. The term blended learning has however emerged in the last two decades along with rapid innovation in educational technology (Chew, Jones \& Turner, 2008). Most educators and writers consider it a blend of face-to-face learning and online learning or a 


\section{Nordic Journal of Modern Language Methodology}

combination of a physical and a virtual learning environment (Garrison \& Kanuka, 2004). For the purposes of this study, blended learning is defined as a mixed approach to course and syllabus delivery combining online and campus-based tuition and coordinated through a VLE. In 2007, an article by Allen, Seaman and Garrett (in Stacey and Gerbic 2009, p. 2), used the term hybrid learning for courses where 30 to $70 \%$ of the content is delivered online. Blended learning seems to be a dominant trend in higher education and is seen as one method to mediate learning in and across different social worlds (Lund, 2003; Haugestad, 2004).

\subsection{Problem Statement and Research Question}

Since the data collection phase for our project in 2019, blended learning has become "the new normal" for university education. At the start of the autumn term in 2020, nearly all institutions of higher education globally were preparing to run courses online or, to a lesser degree, as blended learning with course meetings limited due to Covid-19 restrictions. As a result, institutions and lecturers have had to realign their course offers to take account of the current situation. Students and lecturers have been forced into blended learning courses and the study patterns they demand due to external factors rather than as a result of pedagogical decisions. In this sense, the current situation is not entirely dissimilar to the sample in this study.

The ideal situation is for a relatively seamless transition from traditional campusbased teaching to blended and/or online learning. However, groups transitioning to "the new normal" provide a synchronic snapshot of a cohort being forced to change course organization and study patterns due to entirely external factors. This study aims to examine the experience of a single cohort of students to identify trends in student perceptions and experience. Moreover, the paper analyses the data in order to extract potential benefits from the student insights and responses. Further, it examines course forms and components for future course runs using blended learning. The mixed-method quantitative and qualitative analysis may provide guidance for lecturers and students as they prepare for an extended period of new study patterns and the potential financial results of periods of economic stagnation. 


\section{Nordic Journal of Modern Language Methodology}

The main research question this study aimed to answer is as follows:

What are student preferences within blended learning?

This can in turn can be expanded by a series of research questions: (1) How do students experience blended learning based on this limited sample? (2) Is there a significant difference in the student experience of campus-based and online learning in the sample? (3) Are there specific components that students experience as more suitable to campus-based or online learning based on the sample? The survey and interview responses are presented in section 3, Results, and then discussed in section 4, Discussion. In section 4.2, Implications, the discussion will be used to provide a set of recommendations for teaching practice and for further study.

\section{Method}

The survey results show how a sample group of students experience online learning compared to classroom learning in the blended learning course for trainee teachers in a municipality in Norway between 2018 to 2019. The study was approved by the data protection authorities, Norsk senter for forskningsdata (NSD), and all applicable privacy protection measures were taken.

\subsection{Sample}

The main research group consisted of 18 respondents out of a group of 28 students, a response rate of $64 \%$. All 18 students answered all seven questions in the survey. Four students were selected for interviews to represent the various views reported in the survey. These students were qualitatively deemed representative of the positions in the sample. Two of the interviewees favored online teaching (Students A and B) and two interviewees were representative of respondents broadly in favor of campus-based classroom teaching (Students C and D). The sample has not been organized or analyzed in terms of age or gender. In part, this is because females are overly represented in trainee teaching cohorts and the profession as a whole. Moreover, the modest sample size and response rate meant that any quantitative analysis on this basis was deemed unrepresentative of any larger crosssection of trainee teachers or students as a whole. Semi-structured interviews were then 


\section{Nordic Journal of Modern Language Methodology}

carried out and transcribed. In these interviews, further comments were recorded regarding respondents' blended learning experience.

\subsection{Data collection:Survey}

The following questions constitute the survey and were later elaborated on in semistructured interviews (see Table 2). Both the survey and the interviews were conducted in Norwegian and have been translated by the authors. The survey was sent out to all the 28 students by e- mail. See Table 1 for question numbers, wording of questions and types of answers.

\section{Table 1 Survey Questions}

\begin{tabular}{lll}
\hline \hline $\begin{array}{l}\text { Quest } \\
\text { ion }\end{array}$ & Question wording & Answers \\
\hline 1 & "What was it like participating in online teaching?" & Short answers \\
2 & "What was it like participating in classroom teaching compared with & Short answers \\
& online teaching?" & \\
$3 \mathrm{a}$ & "Which setting do you prefer for lecturer-student dialogue?" & Classroom, online, no dif \\
$3 \mathrm{~b}$ & "Which setting do you prefer for student-student dialogue?" & $\begin{array}{l}\text { Classroom, online, no dif } \\
\text { ference }\end{array}$ \\
$4 \mathrm{a}$ & "Which setting do you prefer for lecturer-student cooperation?" & $\begin{array}{l}\text { Classroom, online, no dif } \\
\text { ference }\end{array}$ \\
5 & "Which setting do you prefer in terms of your own contribution and & $\begin{array}{l}\text { Classroom, online, no } \\
\text { difference }\end{array}$ \\
& participation?" & \\
7 & "Compare how you learn online with how you learn in the classroom." Short answers
\end{tabular}




\section{Nordic Journal of Modern Language Methodology}

Questions 1 and 2 were open questions. The students were asked to write two or three sentences in order to comment briefly on how they experienced online teaching and campus-based classroom teaching in this course. The responses were collated initially in terms of the general overall response to the medium, i.e. online or campus-based instruction. The data has then been organized into four categories based on a keyword textual analysis. The keywords have in turn been collected into category groups: classroom environment, flexibility, organization, and social relationships.

Questions 3-5 interrogate both perceptions and preferences concerning i) dialogue and cooperation between lecturer and student, and ii) dialogue and collaboration between students. The bases for these terms and categories are elaborated in the respective tables and in section 3, Results. In these questions, three alternatives were given and the students were asked to underline the one they favored the most; online, classroom, or no difference. The same options were given for the fifth question which was linked to the students' effort and participation in the course. Question 6 attempted to elicit preferences in terms of course and teaching components. The data has been organized into responses regarding tasks, assignments, lectures, and course meetings, after a textual analysis. Question 7 asked respondents to rate the three options_classroom, online, and blended-into an order of preference: first, second, and third.

\subsection{Data collection: Interviews}

Eleven out of 18 students volunteered for further interviews. In order to reflect the results of the survey and represent the differing views in the survey, four representative students were selected by the lecturers. Their ages were from 25 to 42 ; however, neither gender and age have been used in the data analysis.

The four student interviews were semi-structured. See Table 2 for a list of questions. Most questions were related to their answers in the survey, allowing for more detailed comments that are used as examples in the discussion of the student responses. 


\section{Nordic Journal of Modern Language Methodology}

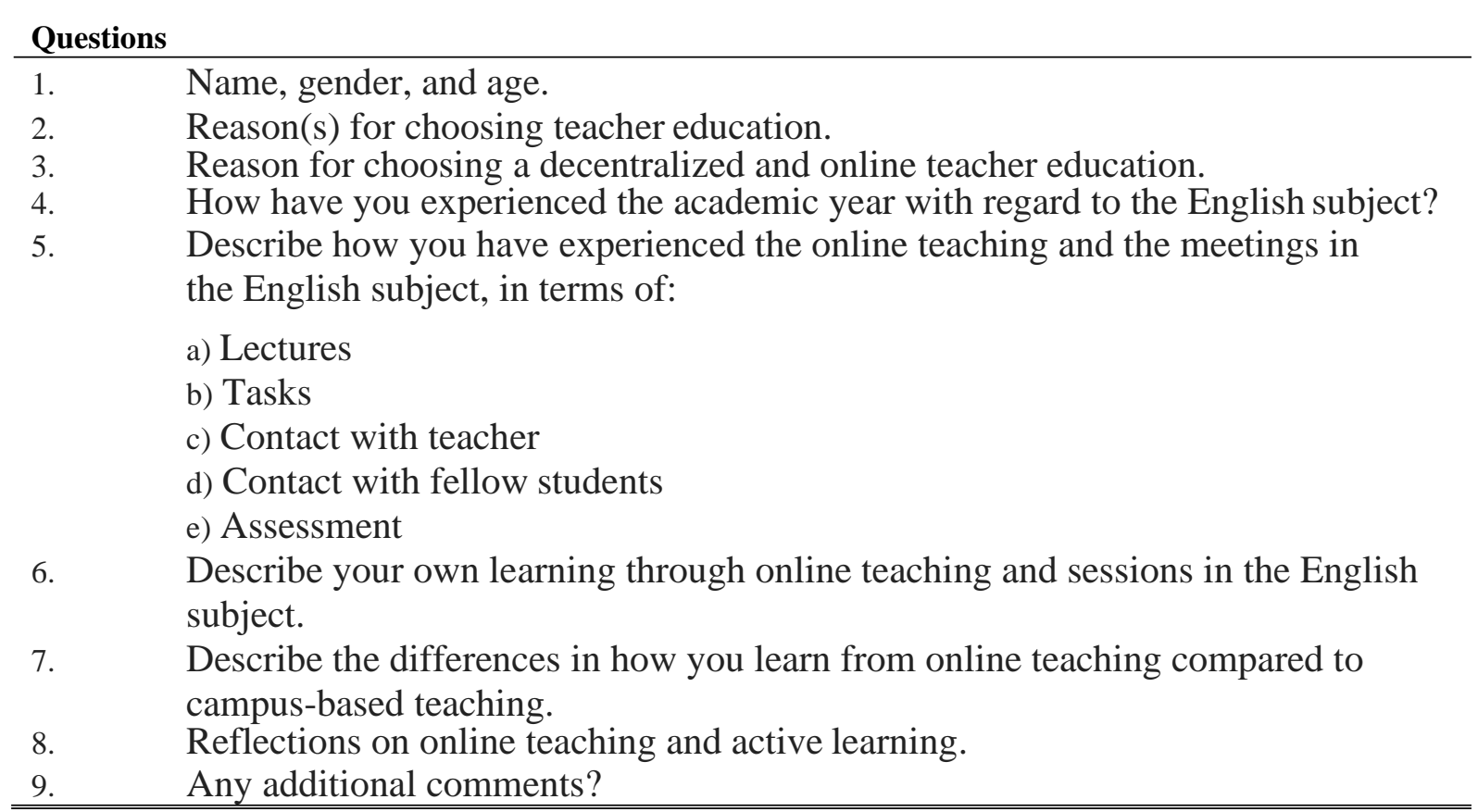

The interview guide consisted of five main parts. The introductory part clarified the main reason for the interview, including a question on why they had chosen a blended learning teacher-training course (Table 2, Questions 1-3).

\subsection{Data analysis}

Mixed methods build on the strengths of both quantitative and qualitative methods (Creswell, 2012). The combination of these two methods is used to add expanded dimensions and present more reliable results (Dörnyei, 2007). An initial quantitative textual analysis provided the basis for the collection of keywords into categories for Questions 1, 2 and 6. Texts were fed into a text analyzer to produce keywords and keyword density (Adamovic, 2006).

In the interviews, data was collected primarily according to qualitative research questions (see Table 2) and during the main stages in an interview investigation (Kvale, 1996). In order to ensure reliability, qualitative research may not be linked to universal truths as in a more quantitative approach according to Kvale (1996). However, the goal is to make generalizations about blended learning based upon this case study. It is hoped that the 


\section{Nordic Journal of Modern Language Methodology}

findings presented here will suggest further investigation into student responses to blended learning environments.

\subsection{Ethical considerations}

This study has been given the consent of the NSD. Relevant information about the research was given to the participants before the project. Participation was voluntary and required written consent. Guidelines from the NSD have been followed concerning both video recordings and transcripts. Transcripts and results have all been anonymized. In addition, data from the surveys has been processed according to guidelines and personal information has been deleted.

\section{Results}

In an environment that provides an appropriate mix of online and campus-based tuition, a clear majority of the students seemed to favor the use of blended learning. This was indicated by both surveys and interviews. In the surveys, most students expressed generally positive opinions concerning the use of online tuition. The following section describes the student responses in greater detail.

\subsection{Question 1 "What was it like participating in online teaching?"}

An initial quantitative textual analysis provided the basis for the collection of keywords into categories presented in Table 2 . Texts were fed into a text analyzer for initial analysis for keywords and keyword density. The quantitative results of the survey are remarkably positive. Approximately 10/18 responses (56\%) said blended teaching is a good method. Indeed, 100\% of respondents were positive to the method, but some qualified their statements with such factors as flexibility, need for preparation, teaching style, and ease of participation. These responses have been duly gathered into the following four categories for analysis:

1) classroom environment (e.g. easy uses 5, 0,6\% density; stressful 1, 0,1\% density; distraction $1,0,1 \%$ density),

2) flexibility (e.g. flexible 4, 0,5\% density),

3) organization (advance, planning, information, prepared, structure $=$ total 6 uses at 
$0,7 \%$ density), and

4) social relationships. These categories are used in Questions 1 and 2. Moreover, the concept categories are returned to throughout the data analysis.

Classroom environment is a category encompassing several types of comments and linked to keywords such as easy, quiet, stressful, and distraction. The category analyzed commentary regarding the student experience of the classroom environment, in both campus-based and online classrooms. Respondent 7 described the process as "less stressful than classroom instruction". This position is voiced by a total of 3 out of the 18 respondents (17\%), with peace and quiet being keywords. One respondent only, however, asserts it is "easy to be distracted and/or do other things" during online instruction. The interviews corroborated these claims. Student A emphasized the peaceful quality of online instruction, saying that: "It's like you're getting rid of all the distractions - you can take it at your own pace - you can get rid of all the distractions."

Flexibility is a key category in student perceptions of participating in online education. It encompasses statements using keywords such as flexible, family, location, and illness. As a category group, these terms often refer to external factors rather than internal (classroom environment, organization). Illness, family and small children, work, and geographical location were all important factors in this response group. Over 50\% (10/18) of respondents mentioned factors collected here under the category of flexibility. For example, Respondent 10 also notes that: "For me, it works better than traditional teaching, since I can then myself structure and manage my working hours during lectures and in group work." This seems a significant and expected result. The interviews corroborate the importance of flexibility in the sample group.

Organization is a third concept category mentioned by 6/18 (33\%) of the sample. This term refers to internal factors e.g. course and subject organization for teaching and instruction rather than flexibility in students' own lives outside of school. It consists of responses including keywords such as advance, planning, information, prepared, structure (total 6 uses at $0,7 \%$ density). For many respondents, online teaching requires careful planning: "[It] requires that you are well prepared, which in turn leads to better quality over the preparation" (Respondent 1). Insisting on preparation may well aid learning. 


\section{Nordic Journal of Modern Language Methodology}

Respondent 14 emphasizes that: "If structure and info in advance is good, usually lecture is also good. Good planning and advance information in good time are key words."

In the interviews, Student B mentions that some students do not thrive in an online environment, stating that "there may be many who are not structured enough to handle the work that just makes them unable to keep up." This, however, seems a response to external factors such as work, family, travel, illness etc. rather than internal factors pertaining to the course and its organization. Respondent 15 underlines the benefit of such flipped techniques, noting that students prefer recordings "so that everyone can see it - record several times, rewind a bit, make notes along the way and pause."

Social relationships is the final category in this survey and interview analysis. This construct overlaps with the first category, i.e. classroom environment. This is clearly problematic. However, where classroom environment refers to internal factors within the course organization, social relationships is a broader and primarily external category including social relationships as perceived outside of the classroom in terms of student-student relationships and pastoral care, e.g. lecturer-student relationships. Perceptions of social relationships are explored in greater detail in questions 3a, 3b, 4a and 4b. Many students underlined the critical importance of course meetings in developing these social bonds. In the interviews, for example, Student $\mathrm{C}$ is: "[...] very happy that we have the course meetings $[\ldots]$ nice that we have this combination then, that it is online and meeting-based so that you actually get to meet the teachers and the others in the class". Moreover, some students built study groups that not only helped develop social relationships but also improved their experience of the classroom environment for online instruction and lectures. Student C develops this in the inter- views:

[...] we are a group that has sat here in teams (at the study center). Since we started we have been sitting here every Tuesday, Wednesday, and Thursday and then we have had each other to rely on, had each other to discuss with [...] (Interviews, Student C)

This suggests the potential mitigation of online disconnection and isolation through the creation of study groups and student management of the online environment. 


\subsection{Question 2 "What was it like participating in classroom teaching compared with online teaching?"}

A textual analysis of a comparative question cannot focus on single-word occurrences and percental density as in Question 1. The comparative statements appear in "it is easier to" (7 statements) formulations etc. However, a qualitative analysis of the short answers suggests a mixed response to online teaching in comparison with traditional classroom-based education. Thirteen of the 18 respondents (72\%) find advantages and disadvantages to both, with several claiming there is little difference. Respondent 11 sums up concisely: "Lecture sections of teaching work just as well online as in a classroom". There are however various possible interpretations of these results and this data must be analyzed with caution. A clear majority of respondents find no clear difference between campus-based and online tuition, at least in terms of instructor-provided content.

Five of 18 responses $(28 \%)$ seem to favor online teaching unequivocally.

Respondent 9 states "I prefer online teaching to classroom-based teaching”. Similarly, Respondent 10 finds "clear benefits to online teaching in terms of accessibility. You get more peace of mind to follow the teaching without disturbances from the typical classroombased”. Some respondents even state a preference for group work online: “Group work up to 5 people I think works better online" (Respondent 10). This may surprise many educators as it is generally expected that social interaction works better in real life. Of course, many respondents qualify their statements with a need for the traditional classroom. Respondent 13 states "I like online teaching better, but it's good with classroom teaching on a regular basis". In contrast, $4 / 18$ responses ( $22 \%$ ) state a clear preference for campus-based teaching. In sum, it seems clear that little divides students in terms of their experience of participating in online and campus-based teaching. However, that nearly $30 \%$ have an unqualified preference for online teaching is significant.

One clear trend in the survey data for Question 2 is that greater focus was placed by respondents on two categories: classroom environment and social relationships. They have been differentiated as referring to (1) experience of being in the classroom whether online or campus-based, as opposed to (2) experience of social relationships external to the classroom environment e.g. assignments and group work to be carried out outside of the classroom, study groups and social activities and friendships external to the classroom. This 
trend points to the fact that organization and flexibility - i.e. structure internal to the course, subject and teaching, and structure external to these factors - are of less importance in terms of student perceptions and experience when comparing campus-based classroom teaching to online tuition. However, caution must be applied in making any generalization from such a small sample size.

Classroom environment as a category response includes components such as asking questions, discussion, maintaining focus, etc. Thirteen out of 18 responses (72\%) mention these components. Out of those 13 responses, 7 (54\%) favour online settings whereas 6 (46 $\%$ ) favour campus or classroom-based settings. Positive responses include a description of a calm environment with a lack of distractions: for example, that there is a "better calm over the teaching when it is online" (Respondent 1) or that "You get more peace of mind to follow the teaching without disturbances as compared to the typical classroom-based instruction" (Respondent 10). Some of these responses elaborate on this calm and lack of distraction, arguing that the online environment allows for better contact between participants and/or instructors. Indeed, Respondent 17 concurs that "Online, teachers and students can quickly talk to each other during group answers". In addition, Respondent 18 suggests that this leads to a greater degree of democracy and educational equality: "An advantage of online versus classrooms is that everyone is equal without anyone "taking up more space" than others."

Six out of the 13 responses (46\%) unequivocally support ease of participation, and discussion in campus-based classrooms, however. Several respondents comment on procedures around asking questions and dialogue. Respondent 2 states that it is: "Easier to ask questions/discuss in classrooms than online.” Respondent 17 agrees and underlines the immediacy of contact, as it is "easier to answer questions in classroom-based teaching (just raise your hand, and you get answered)". This is an expected outcome for many observers. Perhaps what is surprising in this data is that an equal number of respondents find online settings equally advantageous. Another component to highlight is the responses suggesting the students found it easier to maintain active participation in an online environment, at least for a subset of students.

Whereas freedom from distraction is mentioned in responses in favor of online settings, many respondents underscore the fact that they are "better able to maintain focus 


\section{Nordic Journal of Modern Language Methodology}

over time in a classroom" (Respondent 11) or that "collaboration with fellow students, $[\ldots]$ is easier to achieve in classrooms" (Respondent 8). One group of students responded to this perceived challenge by forming a study group in order to meet physically for online sessions.

If you want to sit with fellow students, it is possible by attending the study center, something my group has done $95 \%$ of the time. Then it has been possible to discuss and work with fellow students. (Respondent 4)

Respondent 4 points out that you have the choice of joining a group and providing classroom- style social learning.

Social relationships considers social interaction at course level and not just classroom- level, whether that classroom is campus-based or online. In this course, course meetings (often referred to as gatherings) mitigated the online classroom and appear to play a critical function for the group. The course was delivered as blended learning, with 2-3 course meetings per term. Respondent 3 underlines the importance of course meetings: "Meeting fellow students in real life is naturally much nicer". This sense of belonging is critical for learners ac- cording to Deci and Ryan (2000). In total, twelve out of 18 responses (67\%) explicitly flag for class belonging and social cohesion as critical components of successful education. This suggests that social cohesion and belonging are a major part of student perceptions of differences in participating in courses on campus compared to online. Respondent 5 sums this up, stating: "You lose the social that is in a classroom."

In questions $3 \mathrm{a}, 3 \mathrm{~b}, 4 \mathrm{a}, 4 \mathrm{~b}$, and 5 , the students were asked to mark the alternative they preferred by choosing a) classroom, b) online or c) no difference. Both the dialogue and cooperation were divided into two parts: lecturer-student and student-student. Dialogue refers to two- way communication and includes a range of discourses in both categories.

\subsection{Question 3a "Which setting do you prefer for lecturer-student dialogue?"}

Lecturer-student dialogue (see Table 3) includes one-to-one communication in a whole-class classroom environment whether this constitutes lecturing or questions being asked by the class, discussion generated from these types of questions, and monitoring activities in giving oral feedback when students are working in pairs or small groups. Moreover, written 


\section{Nordic Journal of Modern Language Methodology}

feedback on submissions should also be included in this category, where they have occurred during classroom time and can therefore be considered part of the classroom environment. An example of this is direct feedback given on group work in online settings. These are all types of communication that are prevalent in traditional teaching and lecturing in a physical classroom.

Table 3 gives both a breakdown in terms of actual numbers in the sample, in addition to those numbers as a percentage.

Table 3 Question 3a "Which setting do you prefer for lecturer-student dialogue?"

\begin{tabular}{lll}
\hline Preference & Number & Percentage \\
\hline Classroom & 3 & 16,67 \\
Online & 5 & 27,78 \\
No difference (ND) & 10 & 55,56 \\
\hline Note & &
\end{tabular}

A majority (56\%) responded with No difference (ND) concerning the dialogue and contact between lecturer and student. This may corroborate the fact that campus-based classroom practice and online tuition share and privilege similar forms and methodologies. These stu- dents obviously found the teacher equally accessible for dialogue online and in the classroom. (There were three course meetings, in toto 6 days per semester.) Less than a third (28\%) found it easier to have a dialogue with their lecturer online. Only 3 out of 18 students (17\%) responded that they prefer to have a dialogue with their lecturer in the campus-based classroom.

In the interviews, both Students C and D felt more nervous when speaking or asking questions during online lectures, something they said made them less active. Questions, comments or immediate feedback were, according to these students, more difficult to give when in an online setting. Both Student C and D expressed that this situation felt less difficult when in a classroom. For example, Student $\mathrm{C}$ states that it is "more likely that I get everything with me in a classroom situation than if I sit online". Speaking English to others and in front of others seemed easier when being able to see fellow students and lecturers in a live environment. In sum, it seems that those students who found dialogue with teachers difficult online, found this factor disruptive to their learning experience. 


\subsection{Question 3b "Which setting do you prefer for student-student dialogue?"}

Student-student dialogue maps oral participation and oral peer assessment in group work and tasks in the classroom environment. This rarely occurred in the main teaching room in the online classroom environment. Many students reported being told to keep their audio off when in the main virtual teaching environment, posting questions instead on the "textwall" or chat function. However, student-student dialogue characterized all task-based activities and peer assessment in the classroom environment. Table 4 displays the responses for preference from the sample.

Table 4 Question 3b "Which setting do you prefer for student-student dialogue?"

\begin{tabular}{lll}
\hline Preference & Number & Percentage \\
\hline Classroom & 8 & 44,44 \\
Online & 3 & 16,67 \\
No difference (ND) & 7 & 38,89 \\
\hline Note
\end{tabular}

A large group of respondents preferred student-student dialogue to take place in the classroom (44\%), whereas 39 percent found there to be no difference (ND). This shows that almost half of the students preferred to meet each other and communicate in a physical room rather than communicating online. In the interviews, Student D states that it is "important because we should be able to meet and see each other and get to know each other". It is no surprise that actual physical proximity and contact, rich with extralinguistic content and social context, is stated as a preference for a large part of the respondents (Grabinger \& Dunlap, 1995). To some degree, a social group must function differently and with greater cohesion and inclusivity in a virtual environment. In the interviews, Student $\mathrm{C}$ explains that "there is more when I have to communicate back [...] to work in groups online so I think it is more difficult". This underlines some of the issues of the online setting. For example, there is no one-to-one interaction within the virtual group; instead, all communication goes one-togroup. This in turn may mean it is easier to replace the lecturer-student dialogue with a chat function, than it is to replace the student-student dialogue. However, the challenges of negotiating groupwork and virtual group environments hopefully help develop a mentality of deliberate practice (Erics- son et al, 1993). 


\section{Nordic Journal of Modern Language Methodology}

\subsection{Question 4a "Which settingd oyou prefer for lecturer-student cooperation?"}

In question 4, the use of the terms cooperation and collaboration explores Panitz' (1999) distinction between cooperative learning and collaborative learning. The former, lecturerstudent, is lecturer and classroom practice centred; the latter is predominantly studentcentred. This is a false distinction in teacher education where students are focusing on both teacher practice as well as student-centred practices. However, the distinction is useful as major differences between online and campus-based tuition were perceived. Table 5 organizes the responses after number and percentage.

Table 5 Question 4a "Which setting do you prefer for lecturer-student cooperation?"

\begin{tabular}{lll}
\hline Preference & Number & Percentage \\
\hline Classroom & 5 & 27,78 \\
Online & 2 & 11,11 \\
No difference (ND) & 11 & 61,11 \\
\hline Note & &
\end{tabular}

Two-thirds of the students said there was no difference between classroom and online lecturer-student cooperation. One third preferred the classroom, whereas 11 percent found online the best way to cooperate.

\subsection{Question 4b "Which setting do you prefer for student-student collaboration?"}

The results for this question were surprisingly different to Question $4 \mathrm{a}$ (see Table 6).

Table 6 Question 4b "Which setting do you prefer for student-student collaboration?"

\begin{tabular}{lll}
\hline Preference & Number & Percentage \\
\hline Classroom & 10 & 55,56 \\
Online & 2 & 11,11 \\
No difference (ND) & 6 & 33,33 \\
\hline Note & &
\end{tabular}

More than half of respondents preferred classroom collaboration whereas one third responded that there was no difference. A mere 11 percent considered online collaboration as their best option. It is clear that more students reported a better experience of collaboration in a physi- cal, campus-based classroom than working together online. 


\subsection{Question 5 "Whichsettingdoyoupreferintermsofyourowncontributionand participation?"}

This question points to classroom environment in terms of satisfactory input and involvement in a classroom. It, therefore, constitutes a direct comparison of campus-based and online class- rooms. Table 7 arranges the responses to Question 5 as both actual numbers and percentages.

Table 7 Question 5 "Which setting do you prefer in terms of your own contribution and participation?"

\begin{tabular}{lll}
\hline Preference & Number & Percentage \\
\hline Classroom & 4 & 22,22 \\
Online & 3 & 16,67 \\
No difference (ND) & 11 & 61,11 \\
\hline Note &
\end{tabular}

There appears to be little perceived or experienced difference between levels of input and contribution in campus-based and online classroom environments.

\subsection{Question 6 "Compare how you learn online with how you learn in the classroom."}

The overall response in this question is that $10 / 18$ responses $(56 \%)$ either did not express a clear difference or perceived none. Perhaps of some significance is that only $1 / 18$ responses $(0,06 \%)$ explicitly state that learning is more effective in the campus-based classroom. However, even this sole respondent continues to state that they would then choose to study online in the future regardless. The material here had been collated into new category groupings in order to elicit greater detail about methodology or course components that may or may not work in either or both settings. First, tasks are in-class activities normally conducted in small groups. In this sense, tasks is synonymous with group work (11 uses; $0,87 \%$ ) i.e. collaborative assignments carried out in the classroom, both campus-based and online.

The surprising finding here is that many respondents report that in-class group work functions equally well online. This contradicts responses to Question 3a which show only $17 \%$ favoring online settings for student-student dialogue and $44 \%$ preferring the campusbased classroom environment. Respondent 6 writes: "Group work in Omnijoin also works well". Furthermore, a significant number of responses indicate that the online environment 
is better. Respondent 10, for example, states that: "Group work, on the other hand, works much better online". This corroborates earlier responses in Questions 1 and 2, while contradicting responses to $4 \mathrm{~b}$. This positive response must be considered an unexpected outcome. As a result, caution must be applied in interpreting the data here which seems unreliable. This may be a result of the lack of clarity in category boundaries between dialogue and settings.

Lectures ( 8 uses, 0,63\%) refers to the one-way lecturer-to-student transfer of knowledge typical of most university settings. In the context of blended learning and the survey responses, consideration must be given to recorded lectures. Recorded lectures may by pre-recorded lectures as part of a flipped classroom or recordings of live lectures. While only $4 / 18$ responses $(22 \%)$ explicitly mention lectures in answer to this question, this issue has been touched on in relation to Questions 1 and 2 above. It is clear that traditional lectures work well online. Respondent 6, for example, states that "Online works well when it comes to 'pure' lecture". This is echoed throughout the survey and interview responses. Respondent 4 elaborates in terms of both flexibility and organization: "you can watch lectures regardless of where you are, and that you can watch recordings of lectures several times". Indeed, this flexibility and the potential to watch or re-watch foundational material and/or recorded sessions is an issue highlighted as a result of blended learning.

Assignments (4 uses, 0,32\%) refers to longer group work, projects or both crosscurricular assignments and integrated teaching assignments linked to work placements. These are then carried out outside the classroom and therefore are not considered part of classroom environment, but rather course organization and social relationships. Many respondents emphasize the advantages of working on assignments regardless of setting. Respondent 4, for example, states that he or she "[1]earns best by working on assignments related to topics". Another point made in the survey responses was that having "the same topic in different subjects" (Respondent 4) i.e. working in a cross-curricular fashion was a positive aspect of the course. Students also fulfilled teaching placements and integrated assignments to be carried out during the placement. This caused some difficulties according to Respondent 8: "Before and after the internship period when we were set to collaborate with the internship group it entailed difficulties". However, assignments outside of classroom time generally work well online according to respondents. For example, 


\section{Nordic Journal of Modern Language Methodology}

Respondent 16 affirms that "it is easier to work online with such group work due to distances between the students and also working hours if it is to work outside of lectures".

The classroom (16 uses, 1,26\%) features frequently in survey responses. Course meetings were an integral part of the course offer and organization in this meeting-based blended learning course. One survey respondent highlights their critical role: "Classroom teach- ing/gatherings that we have had have been important at start-up" (Respondent 11). However, the classroom receives both positive and negative responses in the survey. For instance, Respondent 3 privileges "classroom teaching" as "much more effective in terms of collaboration". It is unclear whether this means student-student collaboration as defined in the study. This response is in direct contrast to Respondent 9 who states that "In the classroom I quickly become passive and non-participatory and depend on the lecturer".

\subsection{Question 7 "Which setting do you think best for your own learning as a trainee teacher?"}

The students were asked to prioritize the total learning situation (see Table 8) by numbering the three options from 1 to 3 ( 1 = highest priority).

Table 8 Question 7 "Which setting do you think best for your own learning as a trainee teacher?"

\begin{tabular}{lllllll}
\hline \hline & \multicolumn{2}{c}{ Classroom } & \multicolumn{2}{c}{ Online } & \multicolumn{2}{c}{ Blended } \\
\cline { 2 - 7 } Rating & Number & $\%$ & Number & $\%$ & Number & $\%$ \\
\hline 1 & 1 & 6,25 & 5 & 29,41 & 10 & 58,82 \\
2 & 5 & 25 & 7 & 43,75 & 5 & 35,29 \\
3 & 11 & 62,5 & 5 & 31,25 & 2 & 5,88 \\
\hline
\end{tabular}

Note: Most students gave responses of 1,2 , and 3 . A few however gave 2, 2, and 3, etc. One student did not rank any choice. There are a total of 51 responses for 17 respondents.

Twenty-nine percent said the online lecture was the best way to learn, whereas only 6 percent stated that learning in a classroom was their first option. A clear majority of almost $60 \%$ preferred blended learning. As their second priority, online learning was chosen by 44 $\%$, blended learning by $35 \%$ and classroom learning by $25 \%$.

\section{Discussion}

When asked generally about their favorability toward blended, campus-based, and online learning in the survey the students responded positively toward the blended learning model 
they had chosen. This positivity through the survey, and to a lesser extent the interviews, be- comes more nuanced when asked in greater detail about actual practice. The majority experienced effectively little difference between the physical and virtual classroom and in terms of teacher-centred practice and cooperative learning. In contrast, student-centred practice and collaborative learning were strongly favored as campus-based activities and processes. This could support a return to traditional lecturing in online tuition covering foundational material and collaborative active learning in course meetings, which may well reflect an on-the- ground reality (Bonwell \& Eison, 1991). No further qualified conclusions can be accurately drawn from the overall data. However, some qualified conclusions may be drawn regarding practice and online and campus-based tuition.

\subsection{What are student preferences for blended learning?}

Questions 1 and 2 indicate a strong positive response (72\%) to online teaching. This overall response in Question 1 can be strongly tied to the clear benefits in terms of flexibility. This is not, however, surprising considering the limited options for study for the sample group. In Question 2, what is surprising is that the data indicates a stronger positive response in favor of online teaching over campus-based classroom teaching in the sample. Approximately $30 \%$ in- dicated an unqualified preference for online teaching over campus-based classroom teaching. When comparing campus-based and online teaching, $72 \%$ indicated classroom environment to be a major factor in student experience. However, that response was equally divided in terms of preference. Another critical factor was social relationships with $67 \%$ of responses emphasizing the creation and maintenance of social cohesion to be very important.

In Question 3a, the response indicated little or no difference in terms of lecturerstudent dialogue in the classroom environment. This may be surprising to some educators, but many students find teacher-centred practice and cooperative learning (Panitz, 1999) equally effective when delivered online. However, the interviews indicated that students who found this dynamic difficult or problematic in the campus-based classroom were likely to experience an even greater negative impact online. The potential democratic benefits as emphasized by some respondents must be factored against greater awareness for those who might experience a negative impact. Question $3 \mathrm{~b}$ demonstrated that less than $17 \%$ preferred student- student dialogue online. This question examined specifically classroom 
environments with a focus on in-class tasks normally conducted in breakout rooms. This is a significant result in terms of a clear preference for the campus-based classroom for studentcentred practice and collaborative learning (after Panitz, 1999). It seems clear that Questions 1 and 2 produce a positive response for primarily lecturing in the online classroom, i.e. teacher-centred and co- operative practice. The $17 \%$ positive result (Question 2) that includes a stated preference for group work online must therefore be seen as an outlier.

The data suggests that both cooperative and collaborative learning work best in a campus-based classroom. Only $11 \%$ privileged online settings over campus-based for collaborative student-student learning. The difference, however, was not so marked for lecturer-student cooperative learning. Where flexibility is not considered an important factor, as in Question 1 for example, the results indicate a clear preference for both guided and independent practice in the campus-based classroom. A majority (56\%) prefer, without qualification, campus-based settings for group work, independent practice, and collaborative learning. This is not necessarily a factor lecturers can control at present due to Covid-19 restrictions.

Question 6 indicates that teacher-centred practice and cooperative learning functions relatively normatively in online settings. Both traditional lectures and teachercentred cooperative practice with students working in breakout rooms in order to fulfill teacher-specified tasks appears to be perceived and experienced as relatively similar to a campus-based course. It is unclear from the data exactly how these types of tasks may differ from teacher to teacher, making it difficult to draw any generalizations from the responses. However, it does seem clear that assignments and course meetings as campus-based components are very important in order to develop and maintain learning strategies. This is an expected outcome, but many respondents do stress the use of online settings to continue group work and extra-curricular assignments effectively and with a greater degree of flexibility in terms of external factors and commitments beyond the educational context.

Question 7 shows that $63 \%$ of the sample would choose blended learning as their first preference for education while $69 \%$ put campus-based classroom teaching as the least favored. While the results must be treated with caution due to the small sample size and probable bias of the response due to blended learning being the only option for most of the 


\section{Nordic Journal of Modern Language Methodology}

respondents, some implications may be suggested based on the data.

\subsection{Implications}

First, the perceived benefits of being in a campus-based classroom are not shared by the response group in this study when practice is teacher-centred consisting of traditional lectures and teacher-led tasks. In fact, these course components are those that a majority of respondents often consider better delivered online for differing reasons. For example, lectures can be recorded and re-watched, repeated, and used for revision. In addition, illness and family commitments can be mitigated due to increased course flexibility that accommodates varying student circumstances external to the educational context. Moreover, students have greater control over the classroom environment by choosing to study from home or to form study groups. All of these factors offer students greater control over study patterns for increased self-regula- tion, self-organization, and greater learner autonomy (Zimmerman, 1990; Little, 1995).

Second, however, the loss of social cohesion and more productive student-student dialogue and collaboration is clear from the data analysis. While steps can be taken to mitigate the loss of critical social arenas by creating virtual sites and arenas for socialization into the group, these sites can never entirely replace the context-rich environment of campus-based spaces or off-campus physical meeting sites. While for some educators and practitioners opportunities may be limited at present, creating physical spaces for interaction is important and can clearly improve social cohesion online. However, moving forward, while campus-based meeting opportunities are currently limited, practitioners may need to consider the balance of traditional teacher-centred teaching practices contra a greater degree of student-centred collaborative work. The study and data does not clarify whether this can make a difference in a blended learning setting. While the sample response indicates that students may prefer to do collaborative work on campus or in a campus-based setting, the data also implies that more traditional lecturing could effectively be delivered online. This raises the question as to how course components might be combined to greater effect.

Further work should look at the use of collaborative student-centred and led activities in online settings. Moreover, how to effectively balance student-centred learning and practice with teacher and classroom-centred practice in a blended learning scenario should be a focus 
for further research endeavors.

\section{References}

Adamovic, M. (2006). Online-Utility.org. Utilities for Online Operating System. https://www.online-utility.org/

Bandura, A. (2001). Social cognitive theory: An agentic perspective. Annual review of psychol- ogy, 52(1), 1-26.

Bonwell, C. C., \& Eison, J. A. (1991). Active Learning: Creating Excitement in the Classroom. 1991 ASHE-ERIC Higher Education Reports. ERIC Clearinghouse on Higher Education, The George Washington University, One Dupont Circle, Suite 630, Washington, DC 20036-1183.

Bransford, J. D., Brown, A. L., \& Cocking, R. R. (2000). How people learn (Vol. 11). Washington, DC: National academy press.

Brown, J. S., \& Duguid, P. (1991). Organizational learning and communities-of-practice: Toward a unified view of working, learning, and innovation. Organization science, 2(1), 40-57.

Brown, P. C., Roediger III, H. L., \& McDaniel, M. A. (2014). Make it stick. Harvard University Press.

Bruffee, K. A. (1997). Collaborative learning and the 'conversation of mankind.'. Cross-talk in comp theory: A reader, 393-414.

Bruner, J. S. (1966). Toward a theory of instruction (Vol. 59). Harvard University Press.

Chew, E., Jones, N., \& Turner, D. (2008, August). Critical review of the blended learning models based on Maslow's and Vygotsky's educational theory. In International Conference on Hybrid Learn- ing and Education (pp. 40-53). Springer, Berlin, Heidelberg.

Creswell, J. (2012). Education Research: Planning, Conducting and Evaluating Quantitative and Qual- itative Researc. Boston, MA: Person Education.

Dörnyei, Z. (2007). Research methods in applied linguistics: Quantitative, qualitative, and mixed methodologies. Oxford: Oxford University Press.

Ericsson, K. A., Krampe, R. T., \& Tesch-Römer, C. (1993). The role of deliberate practice in the ac- quisition of expert performance. Psychological review, 100(3), 363.

Garrison, D. R., \& Kanuka, H. (2004). Blended learning: Uncovering its transformative potential in higher education. The internet and higher education, 7(2), 95-105.

Grabinger, R. S., \& Dunlap, J. C. (1995). Rich environments for active learning: A definition. ALT- J, 3(2), 5-34.

Haugestad, A. (2015). Blended learning in English literature (Master's thesis, The University of Bergen).

Holterman, S. (2019). Kortreist lærer. Utdanning, 3, 10-18.

Kvale, S. (1996). Interviews: An introduction to qualitative research interviewing. Thousand Oaks, CA: Sage.

Lave, J., \& Wenger, E. (1991). Learning in doing: Social, cognitive, and computational perspec- tives. Situated learning: Legitimate peripheral participation, 10.

Little, D. (1995). Learning as dialogue: The dependence of learner autonomy on 
teacher auton- omy. System, 23(2), 175-181.

Lund, A. (2003). The teacher as interface. Teachers of EFL in ICT-rich environments: Beliefs, prac-tices, appropriation. $\mathrm{PhD}$. The University of Oslo.

Ministry of Education and Research. (n.d.). Digitalisation strategy for the higher education sector 2017-2021. Retrieved from

https://www.regjeringen.no/en/dokumenter/digitalisation-strategy-for-the- highereducation-sector-2017-2021/id2571085/

Panitz, T. (1999). Collaborative versus Cooperative Learning: A Comparison of the Two Concepts Which Will Help Us Understand the Underlying Nature of Interactive Learning. Retrieved from https://eric.ed.gov/

Panitz, T. (1999). The motivational benefits of cooperative learning. New directions for teaching and learning, 1999(78), 59-67.

Ramsey, C. (2003). Using virtual learning environments to facilitate new learning relationships. Inter- national Journal of Management Education, 3(2), 31-41.

Ryan, R. M., \& Deci, E. L. (2000). Self-determination theory and the facilitation of intrinsic motiva- tion, social development, and well-being. American psychologist, 55(1), 68.

Stacey, E., \& Gerbic, P. (2009). Introduction to blended learning practices. In Effective blended learn- ing practices: Evidence-based perspectives in ICT-facilitated education (pp. 1-19). IGI Global.

Zimmerman, B. J. (1990). Self-regulating academic learning and achievement: The emergence of a social cognitive perspective. Educational psychology review, 2(2), 173-201 